\title{
Proposta de Ampliação de Unidade de Conservação em Tuneiras do Oeste - PR: aplicação de critérios geoecológicos
}

\author{
Proposal for the Expansion of the conservation Unit in Tuneiras do Oeste - State of \\ Paraná, Application Geological Criteria
}

\section{Propuesta de Ampliación de Unidad de Conservación en Tuneiras del Oeste - PR: aplicación de criterios geoecológicos}

\author{
Kamila Walter Ghisso ${ }^{1}$ \\ Maristela Denise Moresco Mezzomo² \\ Marcelo Galeazzi Caxambú ${ }^{3}$
}

\begin{abstract}
RESUMO: Com a preocupação de potencializar a conservação da natureza de Unidades de Conservação, este artigo apresenta uma proposta de ampliação da Estação Ecológica Angico-doCerrado, localizada no município de Tuneiras do Oeste, estado do Paraná. A proposta se pautou em critérios geoecológicos (influência da matriz, aspectos geoecológicos e gestão) e resultou em dois modelos, um considerado ideal e outro considerado intermediário entre o modelo ideal e a atual configuração da Estação Ecológica. Os modelos apresentados buscam evidenciar a necessidade de contemplar elementos essenciais para a conservação da natureza, como a inclusão de nascentes e córregos dentro dos limites da Estação, bem como o formato arredondado, diminuindo assim efeitos de borda, potencializando a conservação das águas e do solo.
\end{abstract}

PALAVRAS-CHAVE: Influência da matriz. Geoecologia. Gestão integrada.

ABSTRACT: With the objective of enhancing nature conservation of Conservation Units, this paper presents a proposal for expansion of the Angico-do-Cerrado Ecological Station, located in the municipality of Tuneiras do Oeste, state of Paraná. The proposal was based on geoecological criteria (influence of matrix, geoecological aspects and integrated management) and resulted in two models: one considered ideal and one intermediate between the ideal model and the current configuration of the Ecological Station.The models presented seek to highlight the need to contemplate essential elements to nature conservation, such as the inclusion of springs and streams within the Station

\footnotetext{
${ }^{1}$ Graduada em Engenharia Ambiental pela Universidade Tecnológica Federal do Paraná (UTFPR), campus Campo Mourão. Endereço: Via Rosalina Maria dos Santos, 1233 - CEP 87.301-899, Campo Mourão, Paraná, Brasil. E-mail: kamilawg@hotmail.com.

2 Professora Adjunta do Departamento Acadêmico de Ambiental da Universidade Tecnológica Federal do Paraná (UTFPR), campus Campo Mourão. Endereço: Via Rosalina Maria dos Santos, 1233, CEP 87.301-899, Campo Mourão, Paraná, Brasil. E-mail: mezzomo@utfpr.edu.br.

${ }^{3}$ Curador do Herbário HCF, Professor Adjunto do Departamento Acadêmico de Ambiental da Universidade Tecnológica Federal do Paraná (UTFPR), campus Campo Mourão. Endereço: Via Rosalina Maria dos Santos, 1233 - CEP 87.301-899 Campo Mourão, Paraná, Brasil. E-mail: mgcaxambu@yahoo.com.br.
} 
Proposta de Ampliação de Unidade de Conservação em Tuneiras do Oeste - PR: Aplicação de...

boundaries, as well as the rounded shape, thus reducing edge effects and potentializing water and soil conservation.

KEYWORDS: Influence of matrix. Geoecological. Integrated management.

RESUMEN: Con el problema de potencialización de una naturaleza de conservación, este artículo presenta una propuesta de ampliación de la Estación Ecológica Angico-do-Cerrado, ubicado en la ciudad de Tuneiras do Oeste, del estado Paraná. La propuesta se basó en criterios geoecológicos (influencia de la matriz, aspectos geoecológicos y gerenciales y de dos modelos, uno considerado ideal y otro considerado intermedio entre el modelo ideal y una configuración actual de la Estación Ecológica). Los modelos buscan evidenciar la necesidad de contemplar elementos importantes para un proceso de conservación, como una inclusión de nacientes y arroyos dentro de los límites de la Estación, así como el formato térmico, disminuyendo así la delimitación, potenciando el almacenamiento de las aguas y del suelo.

PALABRAS CLAVES: Influencia de la matriz. Geoecología. Gestión integrada.

\section{INTRODUÇÃO}

A preocupação em preservar e conservar áreas remanescentes dos biomas brasileiros se tornou uma constante para alguns setores da sociedade que veem nestes ambientes possibilidades de compreensão da dinâmica da paisagem atual e pretérita. No caso do bioma Mata Atlântica, uma situação relevante se refere às áreas de encraves do Cerrado que, no estado do Paraná, tem ganhado destaque em diversos estudos, como nos levantamentos florísticos realizado por Antunes et al. (2009), na Estação Ecológica do Cerrado em Campo Mourão e Paula (2008), em Sabáudia. Também se destacam os estudos de Paula e Fachini (2010) em Sabáudia e os trabalhos de Sanches, Caxambu e Araujo (2012) e Sanches, Caxambu e Locastro (2013), realizados em Tuneiras do Oeste.

No Paraná, os encraves de Cerrado eram originalmente encontrados em diversos municípios, incluindo Sabáudia, Astorga, Paranavaí, Campo Mourão e Tuneiras do Oeste. Nos quatro primeiros já foram realizados estudos mostrando a devastação das áreas e como a biodiversidade pode estar comprometida. Em Tuneiras do Oeste, estes estudos ainda estão em fase inicial, mas mesmo assim o levantamento florístico que está sendo realizado já indicou a presença de diversidade florística, contando até mesmo com espécies raras e ameaçadas (HATSCHBACH et al., 2005; SANCHES; CAXAMBU; ARAÚJO, 2012; SANCHES; CAXAMBU; LOCASTRO, 2013).

Diante disso, a alternativa encontrada pelo ICMbio e pesquisadores para tentar garantir a proteção e conservação do encrave, foi a criação de uma Unidade de Conservação (UC) na categoria Estação Ecológica. Esta alternativa se baseia no fato de que, enquanto UC, a área está legalmente instituída pelo poder público, com o objetivo 
principal de conservar a biodiversidade por meio do controle do uso dos recursos naturais e da degradação do meio ambiente pelo ser humano (BRASIL, 2000).

Para tanto, considerando que as UCs fazem parte de um contexto de paisagem, e que esta é um conjunto dinâmico e sistêmico, entende-se que somente a criação da unidade não é garantia de proteção. Essa interpretação está atrelada ao fato de que é preciso considerar, quando da criação de UCs, a forma, o tamanho e a localização para que a eficácia de proteção seja potencializada. Este entendimento está atrelado à Teoria da Biogeografia de llhas, com foco no contexto geoecológico da paisagem, ou seja, considerando aspectos ambientais de espacialização como distribuição geográfica e influência da matriz tanto na definição da localização como dos limites das UCs.

Diante desta perspectiva de compreensão da UC no contexto da paisagem, foi desenvolvido um estudo sobre a Estação Ecológica Angico-do-Cerrado, localizada no município de Tuneiras do Oeste, região noroeste do estado do Paraná. O estudo resultou em uma proposta de ampliação da área da Estação considerando dois modelos e se baseou em critérios geoecológicos.

\section{MATERIAL E MÉTODOS}

A pesquisa contou com a abordagem sistêmica como método de estudo e buscou estudar de forma integrada as informações contidas na literatura, os dados e informações da área e observações de campo.

Iniciou-se com a definição de critérios geoecológicos a serem considerados na proposta de ampliação da Estação Ecológica. Estes critérios foram baseados na metodologia proposta por Mezzomo (2013), a qual é baseada em estudos reconhecidos envolvendo a Teoria de Biogeografia de Ilhas e a temática da Biologia da Conservação tais como Mac Arthur e Wilson (1967); Wilson e Willis (1975); Diamond e May (1976); Wilcox, (1980) e Primack e Rodrigues (2001). Os critérios geoecológicos definidos envolvem a análise da influência da matriz (uso do solo do entorno da UC), verificação de aspectos geoecológicos (tamanho, formato e arranjo espacial da Estação) e características da gestão (plano de manejo, ICMS ecológico e mosaico). A definição dos critérios resultou em uma legenda (Figura 1) que foi aplicada na área de estudo.

Posteriormente à definição da legenda, foram desenvolvidos levantamentos das características geoecológicas da área, envolvendo informações sobre o substrato rochoso, aquífero, relevo, tipo de solo, classificação climática, fitogeográfica e uso do solo. Estas informações foram obtidas em sites de órgãos oficiais, artigos científicos, teses, dissertações, livros e roteiros metodológicos. Os materiais utilizados envolveram Cartas Topográficas de Araruna (BRASIL, 1990a) e Tuneiras do Oeste (BRASIL, 1990b), com 
escala de 1:50.000; Mapa Geológico do Paraná, com escala de 1:3.000.000 (MINEROPAR, 2001); Mapa Geomorfológico do Estado do Paraná, com escala de 1:650.000 (OKA-FIORI et al., 2006); e Mapa de Vulnerabilidade Geoambiental do Estado do Paraná, com escala de 1:650.000 (OKA-FIORI et al., 2007). Estes dados e informações foram organizados em um Perfil Geoecológico, que se refere a uma técnica de interpretação da distribuição vertical e horizontal da paisagem.

Figura 1 - Legenda com critérios geoecológicos para a elaboração da proposta de ampliação da Estação Ecológica

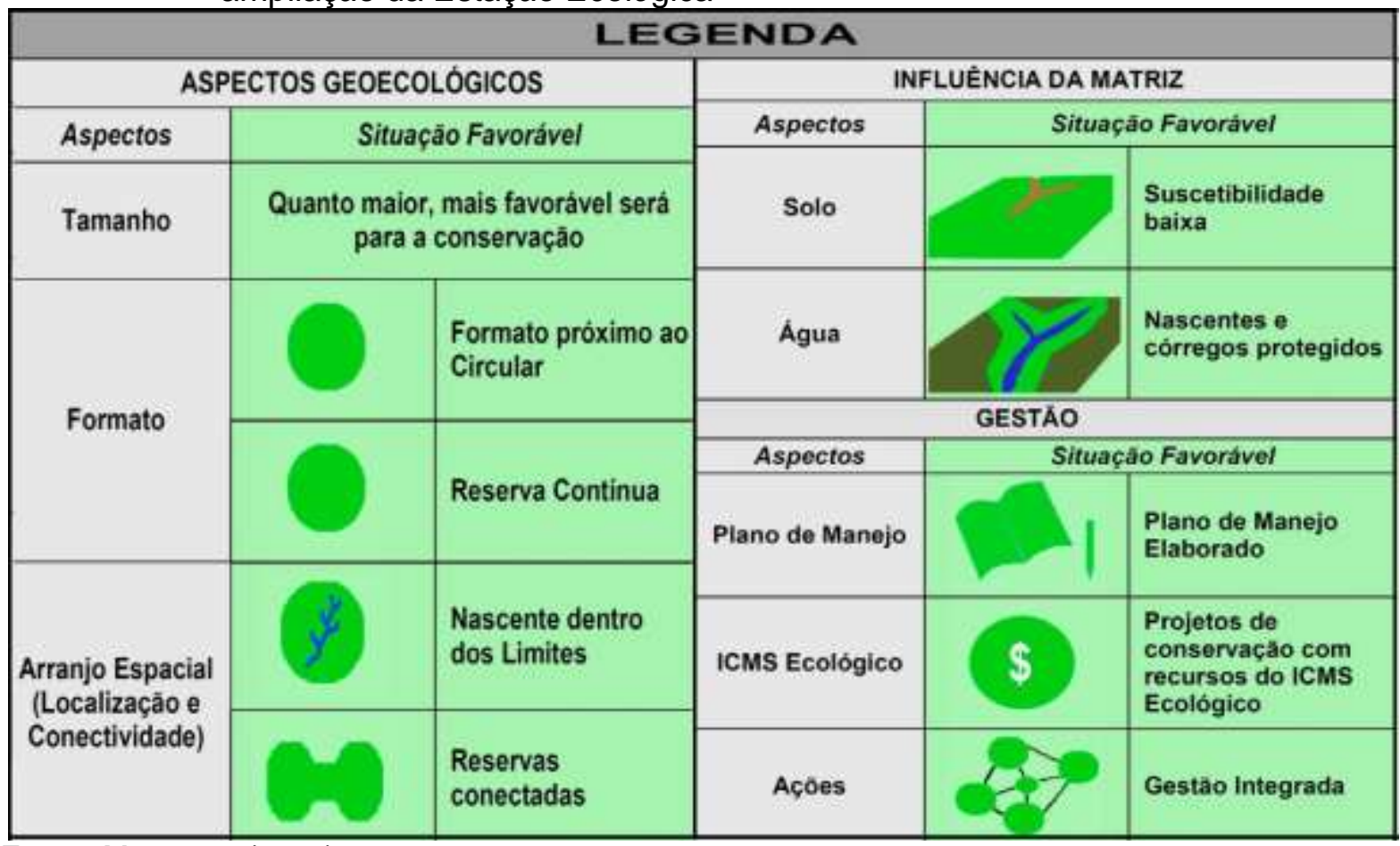

Fonte: Mezzomo (2013).

Também foram realizados trabalhos de campo, nos anos de 2013 e 2014, para observações sobre uso do solo, cobertura vegetal, afloramentos rochosos, drenagem, relevo e possíveis problemas/riscos ambientais. Após a coleta dos dados e informações foram desenvolvidas as análises e feita a proposta de ampliação. Para esta etapa foram utilizadas imagens de satélite de 2013 do software Google Earth, sendo as figuras elaboradas por meio dos softwares Corel Draw e Auto Cad 2013.

\section{RESULTADOS E DISCUSSÃO}

No dia 26 de abril de 2014, o munícipio de Tuneiras do Oeste, com o incentivo do Instituto Chico Mendes de Conservação da Biodiversidade, instituiu a Estação Ecológica Angico-do-Cerrado, com o Decreto $\mathrm{n}^{\circ}$. 102/2014, tendo como objetivo "[...] restaurar e manter a maior amostra de ambiente de Cerrado de Tuneiras do Oeste, favorecer a 
existência e reprodução de espécimes da fauna silvestre local e permitir atividades de pesquisa científica e de educação em ambiente natural" (TUNEIRAS DO OESTE, 2014, p. 20). O Decreto também apresenta os limites da estação com tamanho de aproximadamente 84 hectares e estabelece uma Zona de Amortecimento (ZA) de 200 metros em projeção horizontal a partir do perímetro da UC (Figura 2). A Estação situa-se a, aproximadamente, 14 quilômetros da sede do município de Tuneiras do Oeste, no estado do Paraná.

Figura 2 - Localização da Estação Ecológica Angico-do-Cerrado no município de Tuneiras do Oeste - PR (polígono interno) com a delimitação da Zona de Amortecimento (polígono externo)

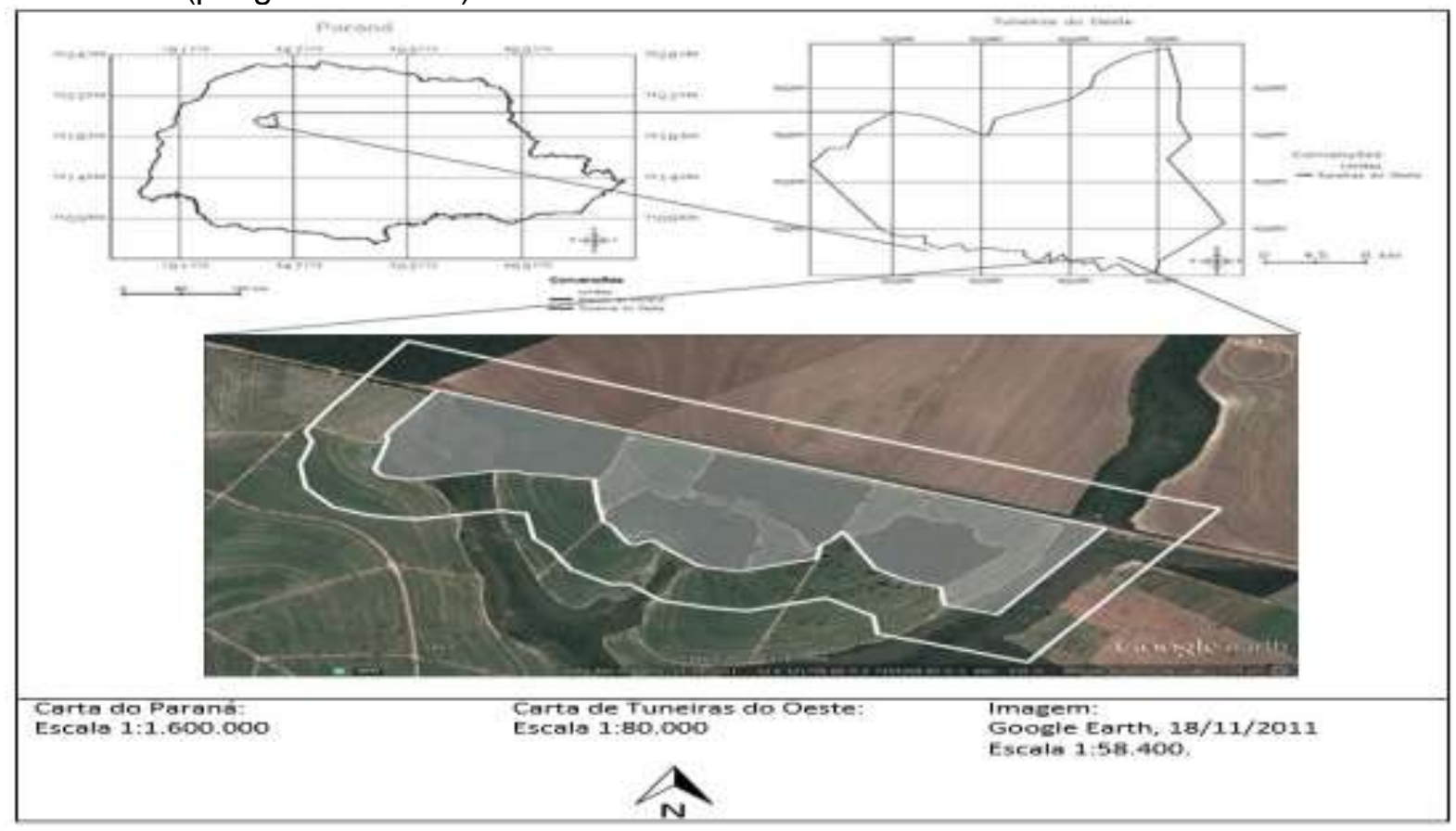

Fonte: Organizado pelos autores a partir de: (GOOGLE EARTH, 2013; SANCHES; CAXAMBU; ARAÚJO, 2012).

O mesmo decreto criou outras três UCs nas proximidades da Estação Ecológica, a Área de Proteção Ambiental das Perobas e os Refúgios da Vida Silvestre das Araucárias e Marabá. Além destas áreas, existe mais uma UC localizada ao lado da Estação, que é a Reserva Biológica das Perobas, a qual soma mais de 8.000 hectares, criada em 20 de março de 2006. A Estação Ecológica é margeada pela rodovia federal BR 487, por propriedades agrícolas e também está próxima a um distrito de Tuneiras do Oeste, denominado Guaraitava.

\section{Proposta de Ampliação da Estação Ecológica Angico-do-Cerrado}

Com a análise da área baseada nos aspectos geoecológicos, influência da matriz e de gestão, foi possível produzir um modelo ideal para ampliação da Estação tendo em vista a 
Proposta de Ampliação de Unidade de Conservação em Tuneiras do Oeste - PR: Aplicação de...

maior eficácia da conservação do solo, da água, da vegetação e ainda - mesmo não sendo o foco da metodologia - das espécies animais (Figura 3).

Figura 3 - Modelo Ideal de Ampliação da Estação Ecológica Angico-do-Cerrado

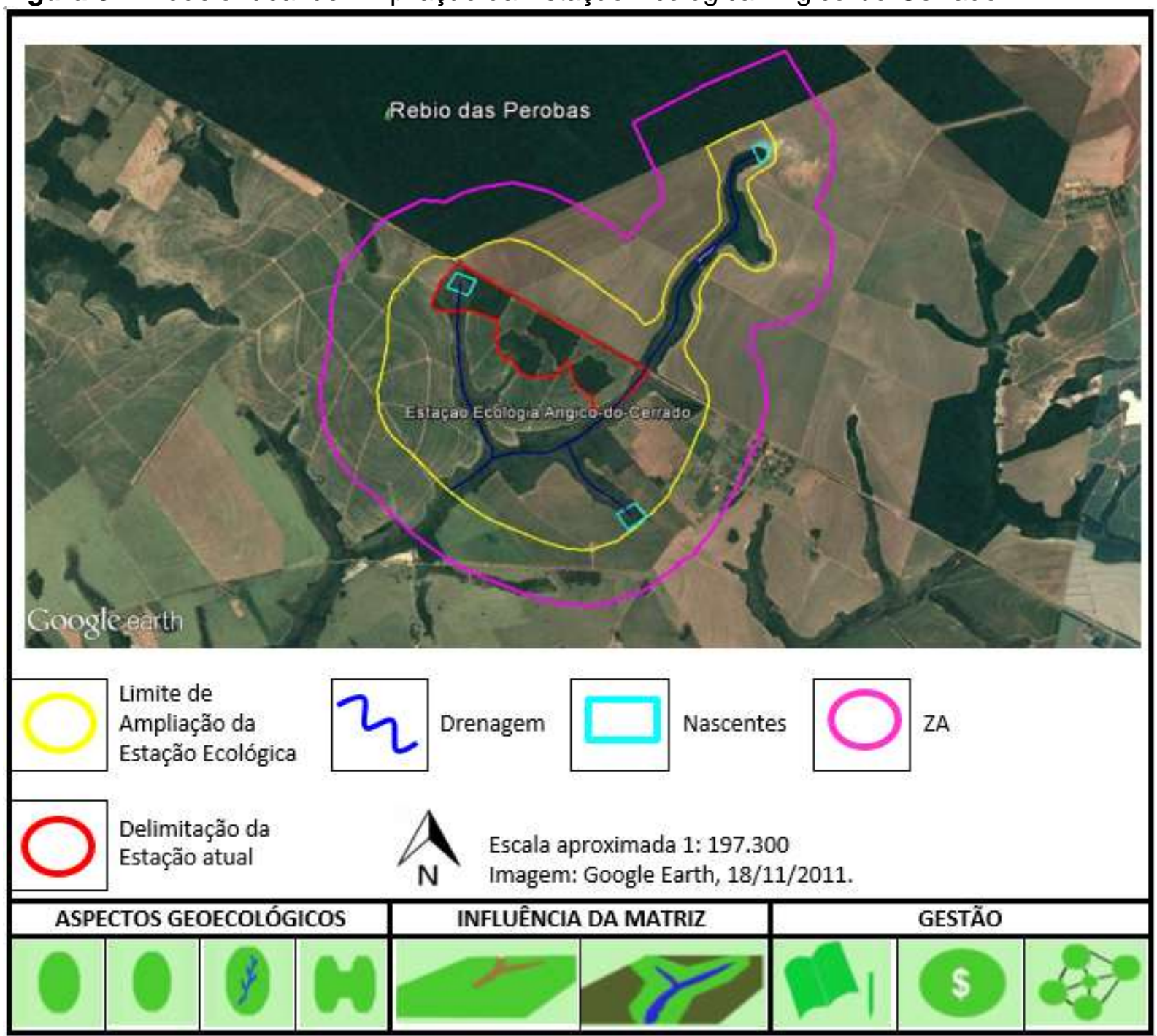

Fonte: Organizado pelos autores a partir de Google Earth (2013).

É reconhecido, porém, que este modelo ideal apresenta algumas dificuldades de execução, como a necessidade de desapropriação de terras, o desinteresse dos proprietários de transformarem suas reservas em UC e a presença da BR 487. Diante disso, foi feita a comparação do modelo ideal com o real e então sugerido um segundo modelo, denominado de intermediário.

Esta não é a configuração ideal, principalmente pelo efeito de borda que a UC poderá sofrer por estar limitada pela rodovia e por ter diminuído de tamanho. No entanto, ela ainda apresenta mais vantagem que um formato retangular ou fragmentado como o atual.

A proposta de ampliação da Estação Ecológica está baseada na concepção de que é preciso maximizar o potencial de conservação da natureza, principalmente no que se refere 
à conservação da água, do solo e da cobertura vegetal. Assim, os critérios geoecológicos definidos envolvem a análise da influência da matriz (uso do solo do entorno da UC), dos aspectos geoecológicos (tamanho, formato e arranjo espacial) e da gestão (plano de manejo, ICMS ecológico, Zona de Amortecimento e mosaico).

\section{Influência da Matriz}

A matriz é compreendida como toda formação vegetal ou não que circunda o fragmento florestal e apresenta uma fisionomia diferente deste. A matriz pode promover a fragmentação florestal, em razão de ações antrópicas como a troca da matriz florestal pela agrícola, provocar poluições e perturbações e se tornar uma barreira para a circulação de animais (PRIMACK; RODRIGUES, 2001). No caso da Estação Ecológica em estudo, a matriz predominante é a agrícola e os riscos ambientais verificados estão atrelados ao uso do solo por culturas temporárias e estradas.

Em relação ao uso do solo, os riscos ambientais verificados envolvem a contaminação das águas e a erosão dos solos. Como a cultura temporária que predomina na matriz em questão é a da cana-de-açúcar, há o controle de pragas e plantas invasoras por uso de produtos químicos (herbicidas e pesticidas) e quanto mais perto dos cursos d'água estão as áreas atingidas pelos produtos, maior o risco de contaminação. Já em relação à erosão, à presença de carreadores e estradas sem manejo conservacionista, aliada ao uso de maquinários agrícolas, estas se constituem como as principais causas de risco devido à compactação do solo, que diminui a infiltração, aumentando o escoamento superficial, o que causa tanto erosão laminar como linear, podendo até mesmo provocar assoreamento dos rios.

Já em relação às estradas, o risco ambiental verificado se refere à ameaça para os animais; tanto no aspecto tráfego, como ruídos, poluentes e resíduos. Esta situação envolve o fato de que há uma BR (BR 487) no limite da Estação Ecológica com a Reserva Biológica das Perobas, que é a maior UC da região. Esta BR apresenta importância para a região, porém cria um conflito pela localização em que está.

\section{Aspectos Geoecológicos}

Os aspectos geoecológicos analisados envolveram o tamanho da Estação Ecológica, seu formato e sua distribuição espacial (localização e conectividade). Segundo Primack e Rodrigues (2001), o tamanho e o local em que as áreas de proteção serão estabelecidas deveriam ser determinados por três fatores: distribuição das populações, valor da terra e esforços de conservação dos cidadãos conscientes. Nesta perspectiva, esses mesmos autores enumeram algumas questões importantes: Qual a extensão que reservas naturais 
Proposta de Ampliação de Unidade de Conservação em Tuneiras do Oeste - PR: Aplicação de...

devem ter para proteger as espécies? É melhor criar uma reserva ou muitas de tamanho menor? Que forma deveria ter uma reserva natural? Quando várias reservas são criadas, elas deveriam estar próximas umas das outras ou bem distantes, e deveriam ser isoladas ou interligadas por corredores?

Considerando estas questões como aspectos-chave para a criação de uma UC, entende-se que quanto maior for a reserva e mais próximo do formato circular, maior será seu poder de atuação na proteção do solo, da água e da cobertura vegetal.

É reconhecido que em relação ao tamanho, se torna difícil quantificar um valor, porém alguns fatores foram considerados na proposição do tamanho apropriado para a ampliação da Estação Ecológica, os quais têm relação direta com o formato da área e o arranjo espacial (localização e conectividade). Assim, considerou-se que a reserva deveria: abranger os fragmentos de Cerrado (que foram o foco para a criação da unidade), os corpos hídricos e as nascentes; manter a borda o mais longe possível dos fragmentos de Cerrado; proteger a maior extensão possível de solo; e seguir o divisor de águas da microbacia.

O aspecto de conectividade do arranjo espacial ficou por conta da formação de um corredor ecológico aproveitando a APP de um dos córregos que fica na margem da rodovia. A conectividade entre reservas, a partir da criação de corredores ecológicos, aparece como uma das melhores soluções para o problema da fragmentação florestal, pois ela possibilita o movimento, melhorando assim o fluxo gênico (PRIMACK; RODRIGUES, 2001).

No entanto, é preciso ter cuidado com a instituição desses corredores, afinal, da mesma maneira que eles podem ser importantes para o fluxo de animais e na dispersão de espécies vegetais, eles também podem se tornar um problema. Isso por que da mesma maneira que elementos interessantes podem passar de uma reserva para outra, elementos "ruins" também podem, como espécies exóticas, epidemias, e diminuição no nível de variação genética das espécies; além de facilitar a ação de caçadores e até mesmo de predadores naturais (NOSS, 1987; PRIMACK; RODRIGUES, 2001).

Neste sentido, os estudos que são realizados para a elaboração do Plano de Manejo de reservas se tornam ainda mais importantes. Esse documento carrega consigo uma relevante carga de informações que definirão as atividades propostas para serem executadas nessas unidades. Portanto, definir se a instituição de Corredores Ecológicos será ou não benéfica, na interação da Estação Ecológica Angico-do-Cerrado com a Reserva Biológica das Perobas, dependerá do confronto das informações presentes no Plano de Manejo de ambas as unidades.

De maneira geral, considerando os aspectos geoecológicos (tamanho, formato e arranjo espacial), a proposta de ampliação da Estação-Ecológica Angico-do-Cerrado seria benéfica não só para a proteção dos relictos de Cerrado existentes no local como, também, na conservação e desenvolvimento das outras UCs vizinhas. Quanto mais próximo dessa 
configuração se apresentar a Estação Ecológica, maiores são as chances de proteção do solo, da água e da cobertura vegetal, além do aumento de habitats para espécies animais, contribuindo assim para o alcance de seu objetivo, que é prioritariamente a preservação da biodiversidade.

\section{Gestão Integrada}

A gestão integrada de uma UC é compreendida na perspectiva de ações conjuntas entre órgãos públicos ambientais, prefeituras, instituições de ensino e ONGs. No caso da Estação Ecológica, três aspectos foram considerados como relevantes para a gestão integrada da área: o plano de manejo, o uso de recursos do ICMS Ecológico e a gestão em mosaico.

O Plano de Manejo da Estação Ecológica Angico-do-Cerrado deverá ser finalizado no prazo de cinco anos, como consta em Lei e tomar como base o documento já existente da Reserva Biológica das Perobas, uma vez que este é capaz de agregar novos projetos específicos, como a abrangência de Corredores Ecológicos e integração com outras UCs, desde que seu foco continue na proteção e no cumprimento dos objetivos específicos.

No decreto de criação da Estação Ecológica consta que será permitida a pesquisa cientifica e a educação ambiental e a possibilidade de se firmar convênios com instituições públicas ou privadas para auxiliar na execução dos objetivos de criação da UC. Então, no plano de manejo da mesma deverão constar os projetos voltados para o desenvolvimento da pesquisa e da educação em ambiente natural na própria UC e em conjunto com as unidades vizinhas. Como este plano já está sendo realizado é possível utilizar os primeiros levantamentos para definir quais e de qual maneira esses projetos serão desenvolvidos e, principalmente, como serão subsidiados.

É no plano de manejo que se indica a destinação do ICMS Ecológico arrecadado por uma UC. Portanto, no documento da Estação Ecológica, deverá constar a parcela que será investida em cada setor de sua gestão. Torna-se importante salientar que o correto uso desses recursos implica em um bom desenvolvimento da unidade. Para Loureiro (2002, p. 4), "[...] talvez uma das contribuições mais promissoras do ICMS Ecológico esteja sendo a busca da construção dos corredores de biodiversidade, malhas ou mosaicos de conservação". Isso porque projetos que são executados em conjunto com outras UCs se apresentam mais eficazes na proteção da natureza. Assim, é indicada uma gestão integrada com outras unidades de conservação, como previsto no Artigo 26 do SNUC (BRASIL, 2000, p. 11), onde diz que, 
protegidas públicas ou privadas, constituindo um mosaico, a gestão do conjunto deverá ser feita de forma integrada e participativa, considerandose os seus distintos objetivos de conservação, de forma a compatibilizar a presença da biodiversidade, a valorização da sociodiversidade e o desenvolvimento sustentável no contexto regional.

Esta situação é bem concreta na região da Estação em estudo, já que existem mais três UCs e uma APA no entorno, sendo elas: a Reserva Biológica (Rebio) das Perobas à noroeste, de caráter federal; e dois Refúgios da Vida Silvestre (Revis), o das Araucárias, à nordeste e o Marabá, à noroeste, ambos de caráter municipal. A APA foi estabelecida em uma faixa de terras de 500 metros a partir dos limites da Rebio das Perobas, coincidindo com a ZA da Rebio que também é de 500 metros em projeção horizontal.

A ZA é uma ferramenta importante no controle de atividades nos arredores da maioria das categorias de UCs. Ela é definida no SNUC (BRASIL, 2000, p. 2) como "[...] o entorno de uma unidade de conservação, onde as atividades humanas estão sujeitas a normas e restrições específicas, com o propósito de minimizar os impactos negativos sobre a unidade". No caso da Estação Ecológica Angico-do-Cerrado, a mesma foi criada com uma ZA de 200 metros em projeção horizontal, coincidindo com uma pequena parte da ZA da Rebio das Perobas. Porém, considerando a formação de um mosaico que abrange, além das outras UCs criadas, a Rebio das Perobas e a Estação Ecológica, seria interessante que se mantivesse a continuidade da ZA desta última, mantendo a Estação Ecológica o mais longe possível da influência das atividades exercidas na matriz agrícola.

$\mathrm{Na}$ medida em que as áreas protegidas forem sendo geridas de maneira integrada, incluindo elaboração conjunta de plano de manejo visando a distribuição do ICMS Ecológico em ações de fiscalização contra caça e pesca ilegal, combate a incêndios, educação ambiental e monitoramento das ZAs, o próprio mosaico poderá fortalecer os corredores ecológicos aumentando, assim, a escala de planejamento territorial e despertando a consciência local para a preservação da biodiversidade. Com isso, práticas de manejo mais apropriadas são incentivadas, diminuindo o efeito negativo sobre os corredores ecológicos e amenizando a ação do efeito de borda. Assim áreas protegidas têm seus limites ampliados, possibilitando a conexão entre UCs e entre mosaicos (LINO; ALBUQUERQUE, 2007).

Além dos benefícios para o meio ambiente, a gestão integrada pode evitar divergências entre os órgãos administradores das UCs quanto à sua forma de atuação, com a criação de um conselho que visa compatibilizar a conservação da biodiversidade com os interesses da comunidade (VASQUES, 2008). Outras vantagens apontadas por Alves et al. (2010, p. 25) são "[...] a flexibilidade de aplicação de recursos financeiros e de contratação de pessoal, além de maior participação da sociedade na gestão das UC". 


\section{Análise Ampliação da Estação Ecológica}

Considerando estas análises, verifica-se que a situação atual da Estação Ecológica quanto aos aspectos geoecológicos não se apresenta como a ideal. Seu tamanho e formato próximo ao retangular excluem três das quatro nascentes dos córregos que a delimitam e deixam-na susceptível à influência da matriz agrícola e ao efeito de borda. Além disso, seu potencial de conectividade com outras UCs é baixo, aumentando o risco de se tornar uma “ilha” em meio à cultura de cana-de-açúcar. Dessa maneira, a ampliação da área se torna uma ação importante para que a UC não falhe em seu papel de conservar a natureza. Baseado nisto, apresenta-se o modelo intermediário para a expansão da Estação Ecológica Angico-do-Cerrado (Figura 4).

Figura 4 - Modelo Intermediário de Ampliação da Estação Ecológica Angico-do-Cerrado

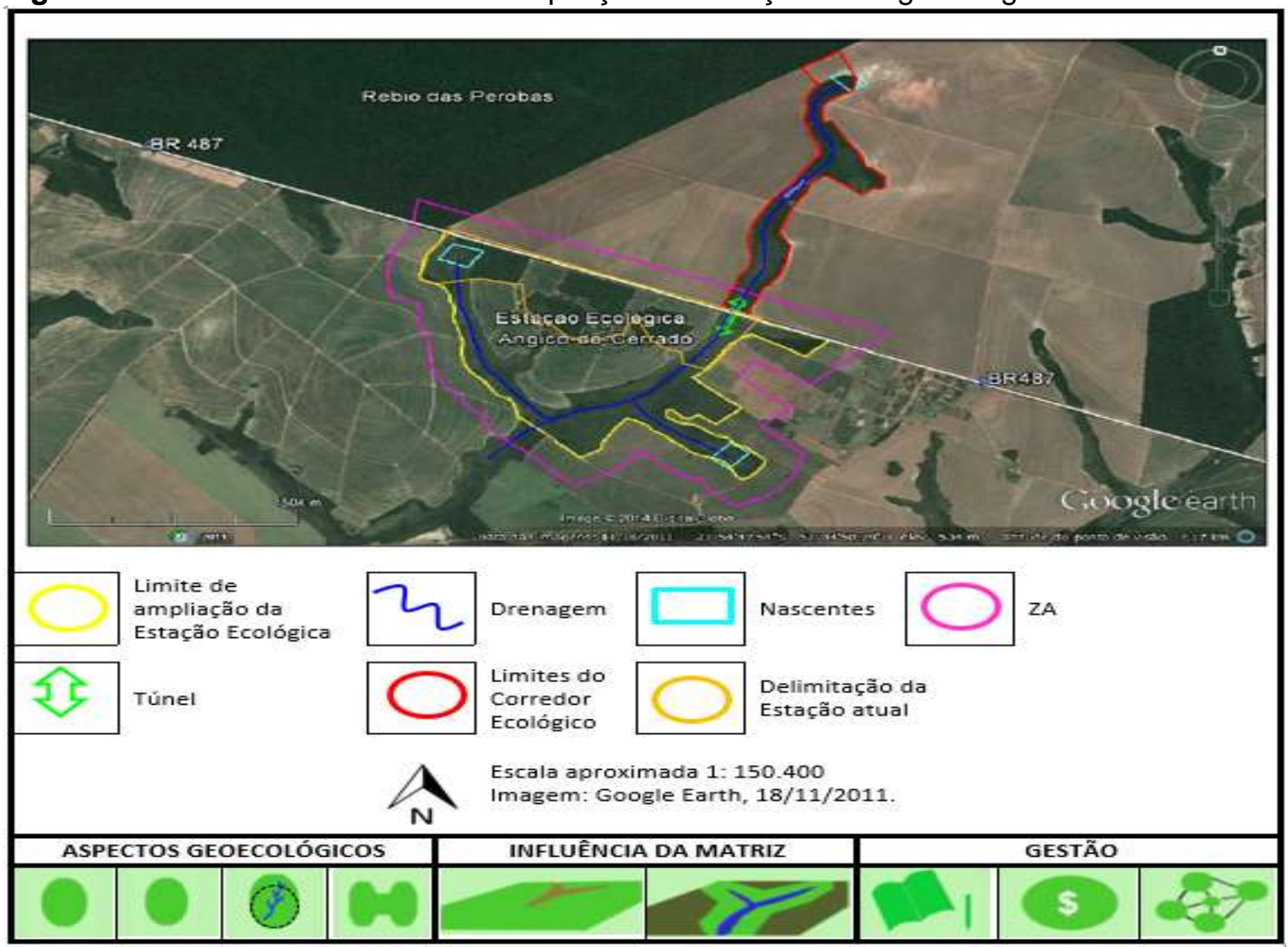

Fonte: Organizado pelos autores a partir de Google Earth (2013).

Neste modelo, o tamanho da estação foi desenhado seguindo os divisores de águas da microbacia, de forma a abranger os fragmentos de Cerrado, uma quantidade maior de área (aumentando a proteção no entorno) e os corpos hídricos. Embora tenha sido necessário adaptar o formato da estação à APP do rio que fica ao norte da estrada, fazendo com que ela ficasse um pouco alongada, ele ficou o mais próximo possível do circular. Este 
Proposta de Ampliação de Unidade de Conservação em Tuneiras do Oeste - PR: Aplicação de...

alongamento no formato foi necessário para proteger o citado curso d'água, bem como sua nascente e, ao mesmo tempo, formar um corredor de conservação que conectasse a Estação Ecológica a Rebio das Perobas. Assim, é possível notar que todos os aspectos geoecológicos (tamanho quanto maior melhor, formato mais próximo possível do circular, todas as nascentes e cursos hídricos protegidos e conectividade com outras unidades) foram considerados.

Atendendo a estes aspectos, juntamente com a ampliação da ZA da estação para 500 metros, este modelo faria com que a influência da matriz sobre a unidade fosse mínima, uma vez que o uso de agrotóxicos e desenvolvimento de espécies exóticas na ZA seria controlado. Este fator, juntamente com o estabelecimento de uma cobertura adequada do solo, atenuaria a ação do escoamento superficial e subsuperficial, evitando o carregamento de poluentes para os corpos hídricos e vegetação nativa e diminuindo as possibilidades de processos erosivos causarem o assoreamento desses cursos d'agua.

Finalmente, ao se tratar da gestão integrada, a proposta ideal apresentaria o plano de manejo finalizado no prazo máximo de cinco anos e elaborado em conjunto com as outras unidades próximas, constando em seu escopo projetos voltados para a educação ambiental, a pesquisa científica, a destinação do ICMS Ecológico arrecadado e a formação de um mosaico de conservação.

No entanto, como afirmado, este modelo ideal apresenta certa dificuldade na sua implantação, começando com a existência da rodovia federal BR 487. Considerando os interesses da geoecologia, o problema é que a rodovia corta a área em duas porções, causando assim sua fragmentação. Desta forma, a BR 487, que já é considerada um risco relacionado a matriz, também passa a ser uma ameaça para dois aspectos geoecológicos: a conectividade e continuidade da UC. Isso porque uma rodovia atravessando uma UC pode levar ao aumento de atropelamento de animais, da poluição e do efeito de borda.

Neste caso, uma solução para tentar manter o formato e tamanho da unidade no padrão desejado seria o desvio do trecho da BR 487. No entanto, esta alternativa é onerosa e poderia causar mais perturbação, tanto para as espécies ali presentes quanto para a dinâmica da paisagem, do que manter uma estrada cortando uma área de proteção.

Outra opção seria a ampliação da galeria por onde passa o córrego presente no local, o qual nasce na margem direita da rodovia e deságua em outro córrego à esquerda desta mesma estrada. Esse alargamento do túnel seria uma alternativa de caminho para os animais sem que eles tenham que atravessar a rodovia para chegar ao outro lado da unidade e também para manter o fluxo gênico de espécies vegetais. Embora não resolvesse a questão da fragmentação e, por consequência, do efeito de borda, esta seria a alternativa mais viável, pelo menos para a proteção e desenvolvimento da fauna local. 
Mesmo diante dessa alternativa, ainda fica a questão da divisão da unidade. Não seria interessante ter uma pequena porção de mata isolada do restante. Assim, apresenta-se uma nova configuração do formato da Estação, onde ela tem como limite norte a BR 487 e, para cumprir com o critério "reservas conectadas", usa a APP do córrego para conectá-la à Rebio das Perobas, como proposto anteriormente, mantendo dentro das possibilidades o formato mais próximo ao circular possível e a nascente protegida. No entanto mesmo com essa nascente protegida, ela não fará parte dos limites da UC, portanto o aspecto de todas as nascentes protegidas dentro dos limites da UC não está sendo aplicado.

Com a apresentação da Figura 4 é possível perceber que a configuração da ampliação da Estação Ecológica não atendeu totalmente três dos cinco aspectos geoecológicos que são sugeridos para que uma UC potencialize a conservação da natureza: formato próximo ao circular reserva contínua e reserva conectada.

No decreto de criação, optou-se por utilizar a BR 487 e as estradas rurais da área para delimitar a estação, o que contribuiu para seu formato próximo ao retangular e sua localização à montante dos cursos d'água. Provavelmente essa configuração foi proposta pensando-se em proteger emergencialmente os relictos de Cerrado.

A mesma BR separa a estação de outras UCs criadas no mesmo ato e ainda da Rebio das Perobas. Assim, enquanto a Estação se encontra na margem esquerda da rodovia, as outras unidades estão localizadas na margem direita, bem como a nascente do córrego, utilizado como uma das divisas da estação.

Diante da impossibilidade de desvio dessa rodovia, se tornou necessário pensar em uma proposta para conectar a nascente à UC, uma vez que não pode ser superficialmente. Sob esta circunstância, se mantém a proposta de um túnel por baixo da rodovia que facilite o fluxo gênico de espécies vegetais e possibilite a passagem de animais. Este túnel, em conjunto com outras práticas, como instalação de radar de velocidade no trecho e ainda espelhos que reflitam as luzes dos faróis e afugentem os animais para dentro das reservas, poderá diminuir consideravelmente o número de morte de animais por atropelamento.

O que impede a reserva de apresentar um padrão contínuo é a presença das plantações de cana-de-açúcar entre os fragmentos, no entanto, no decreto de criação da UC já foi estabelecida a desapropriação de qualquer imóvel rural existente dentro dos limites da estação. Dessa maneira, assim que as plantações de cana forem retiradas do local, será possível executar um Plano de Recuperação de Áreas Degradadas (PRAD), a fim de proporcionar o processo de regeneração da área.

Quanto à ZA, a criação da área não seguiu o padrão de 500 metros da ZA da Rebio das Perobas provavelmente pelo tamanho pequeno da Estação Ecológica, se considerado os mais de 8 mil hectares da Rebio. Outro fator que pode ter interferido é a restrição que uma ZA apresenta e, como a Estação Ecológica é rodeada por grandes propriedades de 
plantio de cana e culturas temporárias (soja, milho), quanto maior fosse a ZA maior seria a restrição quanto à produção. Logo, possivelmente tentou-se conciliar a necessidade de proteção da UC com a de produção das propriedades. Assim, nesta proposta intermediária seria mantida a ZA de 200 metros.

Essas adequações mostram um pouco como é complexo conciliar os interesses econômicos e sociais com os da natureza. Por outro lado, entende-se que se os recursos certos forem aplicados e associados com uma boa administração, é possível fazer adequações. Mesmo não sendo a ideal, essa delimitação ainda é melhor do que a atual, por atender alguns dos critérios geoecológicos apresentados.

\section{CONCLUSÃO}

Mesmo se apresentando como a alternativa mais utilizada para garantir a conservação da natureza no Brasil, a criação de UCs precisa considerar critérios específicos que potencializem a conservação da natureza, ou seja, a criação de áreas não é garantia de conservação, sendo necessário considerar aspectos biológicos, geográficos e ecológicos.

A criação da Estação Ecológica Angico-do-Cerrado teve como motivação inicial a preservação de relictos de Cerrado, principalmente por conterem espécies raras e/ou ameaçadas de extinção. A proposta de ampliação da Estação baseada em critérios geoecológicos foi desenvolvida no intuito de elevar esse nível de proteção, para que além de manter esses fragmentos, seja possível também potencializar a conservação do solo e das águas. Os dois modelos apresentados foram elaborados tendo em vista ampliar e potencializar a conservação da Estação, uma vez que esta é sua função e para isso foi criada.

\section{REFERÊNCIAS}

ALVES, R. G. et al. Análise da gestão das unidades de conservação do sistema estadual de áreas protegidas de Minas Gerais. Espaço \& Geografia, Lavras, v. 13, p. 1-35, 2010.

ANTUNES, E. M. et al. Levantamento florístico da Estação Ecológica do Cerrado de Campo Mourão -PR. In: CONGRESSO DE MEIO AMBIENTE DE AUGM, 6., 2009, São Carlos.

Anais... São Carlos: Universidade Federal de São Carlos, 2009. p. 3-15. Disponível em: <http://www.ambiente-augm.ufscar.br/uploads/A1-057.pdf>. Acesso em: 10 mar. 2016.

BRASIL. Exército. Departamento de Engenharia e Comunicações, Diretoria de Serviço Geológico. Região Sul do Brasil. Cartas topográficas. Araruna. Folha SF.22-Y-C-VI-4 MI2781/4, escala 1:50.000, 1990a.

. Exército. Departamento de Engenharia e Comunicações, Diretoria de Serviço Geológico. Região Sul do Brasil. Cartas topográficas. Tuneiras do Oeste. Folha SF.22-YC-VI-3 MI-2781/3, escala 1:50.000, 1990b.

. Lei no 9.985, de 18 de julho de 2000. Regulamenta o art. 225, § 1o, incisos I, II, III e

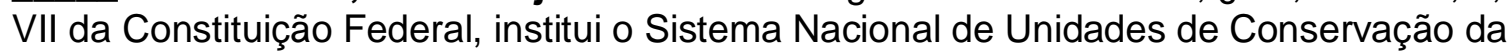


Natureza e dá outras providências. Disponível em:

<http://www.planalto.gov.br/ccivil_03/leis//9985.htm>. Acesso em: 5 ago. 2013.

DIAMOND, J. M.; MAY, R. M. Island biogeography and the design of natural reserves. In: MAY, R. M. (Ed.). Theorical ecology: principles and applications. Oxford: Brackwell Scientific Publications, 1976. p. 163-186.

HATSCHBACH, G. et. al. Levantamento florístico do cerrado (savana) paranaense e vegetação associada. Boletim do Museu Botânico Municipal, Curitiba, v. 66, p. 1-40, 2005.

LINO, C. F.; ALBUQUERQUE, J. L. (Org.). Mosaicos de unidades de conservação no corredor da serra do mar. São Paulo: Conselho Nacional da Reserva da Biosfera da Mata Atlântica, 2007.

LOUREIRO, W. Contribuição do ICMS ecológico na conservação da biodiversidade no estado do Paraná. 2002. Tese (Doutorado em Ciências Florestais) - Universidade Federal do Paraná, Curitiba.

MAC ARTHUR, R. H.; WILSON, E. O. The theory of island biogeography. Princeton: Princeton University Press, 1967.

MEZZOMO, M. D. M. Planejamento da paisagem e conservação da natureza em RPPNs na bacia hidrográfica do Rio Mourão, Paraná. 2013. Tese (Doutorado em Geografia) Universidade Federal do Paraná, Curitiba.

MINEROPAR. Minerais do Paraná. Atlas geológico do Paraná: mineralogia do Paraná. Curitiba: Mineropar, 2001. Escala 1:650.000. Disponível em:

<http://www.mineropar.pr.gov.br/arquivos/File/MapasPDF/atlasgeo.pdf>. Acesso em: 13 fev. 2014.

NOSS, R. F. Corridors in real landscapes: a reply to simberloff and cox. Conservation Biology, Washington, v. 1, p. 159-164, 1987. Disponível em: <http://biology.duke.edu/bio217/2001/aog/noss.pdf>. Acesso em: 23 jan. 2014.

OKA-FIORI, C. et al. (Org.). Mapa de vulnerabilidade geoambiental do Estado do Paraná. Mineropar, 2007. Disponível em:

<http://www.mineropar.pr.gov.br/arquivos/File/2_Geral/Geomorfologia/Mapa_Vulnerabilidade _Geoambiental_PR_650000_2007.pdf>. Acesso em: 10 mar. 2014.

Atlas geomorfológico do Estado do Paraná. Escala base 1:250.000, modelos reduzidos 1:500.000.Curitiba: MINEROPAR, 2006. 59 p. Disponível em:

<http://www.mineropar.pr.gov.br/arquivos/File/2_Geral/Geomorfologia/Atlas_Geomorforlogic o_Parana_2006.pdf>. Acesso em: 20 out. 2014.

PAULA, P. F. Levantamento fitogeográfico da vegetação de cerrado no interflúvio Pirapó/Bandeirantes, Sabáudia-PR. 2008. Dissertação (Mestrado em Geografia) Universidade Estadual de Maringá, Maringá, 2008.

.; FACHINI, M. P. Estudo comparativo da vegetação de cerrado pesquisado por Maack, em 1950 e revisitado em 2007, em Sabáudia, PR. In: ENCONTRO NACIONAL DE GEÓGRAFOS, 16, 2010, Porto Alegre. Anais... Porto Alegre: Associação dos Geógrafos Brasileiros, 2010. p. 1-16.

PRIMACK, R. B.; RODRIGUES, E. Biologia da conservação. Londrina: Vida, 2001.

SANCHES, F. F.; CAXAMBU, M. G.; ARAÚJO, A. A. Levantamento florístico vascular expedito de um remanescente de cerrado no município de Tuneiras do Oeste, Paraná Brasil. In: SIMPÓSIO AMBIENTAL DA UNIVERSIDADE TECNOLÓGICA FEDERAL DO PARANÁ - CÂMPUS CAMPO MOURÃO, 3., 2012, Campo Mourão. Anais... Campo Mourão: UTFPR, 2012. Disponível em: 
<http://www.cm.utfpr.edu.br/ocs/index.php/siaut/IIISIAUT/rt/metadata/156/0>. Acesso em: 26 jan. 2014.

. ; _ _ _ _ LOCASTRO, J. K. Levantamento florístico vascular expedito de um remanescente de Cerrado no Município de Tuneiras do Oeste, Paraná - Brasil. In: SEMINÁRIO DE EXTENSÃO E INOVAÇÃO DA UNIVERSIDADE TECNOLÓGICA FEDERAL DO PARANÁ, 3., 2013, Dois Vizinhos. Anais... Dois Vizinhos: UTFPR, 2013. p. 101-113. Disponível em: <http://www.sei.utfpr.edu.br/>. Acesso em: 13 jan. 2014.

TUNEIRAS DO OESTE. Decreto no. 102, de 26 de abril de 2014. Cria unidades de conservação da natureza, e dá outras providências. Umuarama llustrado, Umuarama, 29 abr. 2014. Disponível em:

<http://www.ilustrado.com.br/Gerador/Emp10/Clientes/llustrado/Documentos/0EQJBD6CZKG8_publicacao_legal\%2001.pdf>. Acesso em: 29 abr. 2014.

VASQUES, P. H. R. P. A aplicação do plano de manejo, zona de amortecimento e corredores ecológicos na proteção da biodiversidade. In: SEMINÁRIO DE INICIAÇÃO CIENTÍFICA DA PUC-RIO, 16., 2008, Rio de Janeiro. Anais... Rio de Janeiro: PỦC-RIO, 2008. p. 1-13. Disponível em: <http://www.puc-

rio.br/pibic/relatorio_resumo2008/relatorios/ccs/dir/relatorio_pedro_vasques.pdf $>$. Acesso em: 2 jun. 2014.

WILCOX, B. A. Insular ecology and conservation. In: SOULÉ, M. E.; WILCOX, B. A. (Ed.). Conservation biology: an evolutionary-ecological perspective. Massachusetts: Sinauer, 1980. p. 95-117.

WILSON, E. O.; WILLIS, E. O. Applied biogeography. In: CODY, M. L.; DIAMOND, J. M. (Ed.). Ecology and evolution of communities. Cambridge: Belknap Press, 1975. p. 522534.

Recebido: setembro de 2016. Aceito: abril de 2018. 